\title{
ACESSIBILIDADE EM SITES DE UNIVERSIDADES FEDERAIS DE PERNAMBUCO: avaliação à luz do Modelo de Acessibilidade em Governo Eletrônico - eMAG
}

\section{Accesibility on Pernambuco Federal Universities sites : evaluation under the Electronic Government Accessibility Model - eMAG}

\author{
Danielle Karla Martins da Silva ${ }^{1}$, Natanael Vitor Sobral ${ }^{2}$, Ludenivson Victor Hugo Soares ${ }^{3}$ \\ ${ }^{1}$ Graduada em Biblioteconomia pela Universidade Federal de Pernambuco. \\ Especialista em Marketing e Mídias Digitais - danikmsila@gmail.com \\ ${ }^{2}$ Mestre em Ciência da Informação pela UFPE - natanvsobral@gmail.com \\ ${ }^{3}$ Graduado em Redes de Computadores pelo Centro Universitário Maurício \\ de Nassau (Uninassau) - : nossaturmanota10@gmail.com
}

\begin{tabular}{|c|c|}
\hline INFORMAÇÕES & RESUMO \\
\hline $\begin{array}{l}\text { Palavras-chave: } \\
\text { Acessibilidade na Web; } \\
\text { Universidades Federais - } \\
\text { Pernambuco; } \\
\text { Modelo de Acessibilidade } \\
\text { em Governo Eletrônico - } \\
\text { eMAG. }\end{array}$ & $\begin{array}{l}\text { Apresenta uma avaliação de acessibilidade dos sites governamentais da } \\
\text { Universidade Federal de Pernambuco (UFPE) e Universidade Federal Rural } \\
\text { de Pernambuco (UFRPE), a partir dos critérios recomendados pelo Modelo de } \\
\text { Acessibilidade em Governo Eletrônico (eMAG) criado pelo Governo Federal } \\
\text { do Brasil. Para o levantamento dos dados sobre os sites foi elaborada uma } \\
\text { planilha como modelo de observação sistemática orientada por categorias e } \\
\text { baseada nos conceitos do eMAG. Ao compilaram-se os resultados, notou-se } \\
\text { que o site da UFPE teve resultado positivo na categoria "identificar idioma } \\
\text { principal da página". O site da UFRPE apresentou bom desempenho na categoria } \\
\text { "fornecer alternativa para áudio". Em contrapartida, os sites das instituições } \\
\text { não atenderam adequadamente a nenhum outro critério de acessibilidade. } \\
\text { caracterizando-os como "sites de baixa acessibilidade". }\end{array}$ \\
\hline INFORMATION & ABSTRACT \\
\hline $\begin{array}{l}\text { Keywords: } \\
\text { Web Accessibility; } \\
\text { Federal Universities - } \\
\text { Pernambuco; } \\
\text { EMAG Accessibility } \\
\text { Model - eMAG. }\end{array}$ & $\begin{array}{l}\text { It presents an accessibility assessment of the government websites of the } \\
\text { Universidade Federal de Pernambuco (UFPE) and Universidade Federal Rural } \\
\text { de Pernambuco (UFRPE), based on the criteria recommended by the Electronic } \\
\text { Government Accessibility Model (eMAG) created by the Federal Government } \\
\text { of Brazil. For the collection of data on the sites, a spreadsheet was created as a } \\
\text { systematic observation model guided by categories and based on the concepts } \\
\text { of eMAG. When the results were compiled, it was noted that the UFPE website } \\
\text { had a positive result in the category "identify the main language of the page". } \\
\text { The UFRPE website performed well in the "provide an alternative to audio" } \\
\text { category. In contrast, the institutions' websites did not adequately meet any } \\
\text { other accessibility criteria. characterizing them as "low accessibility sites". }\end{array}$ \\
\hline
\end{tabular}




\section{INTRODUÇÃO}

A acessibilidade é um processo dinâmico, para além do desenvolvimento tecnológico (TORRES; MAZZONI; ALVES, 2002). Sua concretização associa-se ao desenvolvimento da humanidade, sendo fundamental para que todos sejam incluídos, mesmo diante da existência de diferenças, seja por razão de deficiências ou não. Todavia, com o avanço da internet e das ferramentas computadorizadas, tem-se ampliado as discussões sobre a acessibilidade em âmbito digital, especial, nos websites de instituições públicas, que devem fornecer informações a todos os seus cidadãos, sem distinção.

Motivado por essa conjuntura, o presente estudo tem por intuito apresentar uma avaliação de acessibilidade dos sites governamentais da Universidade Federal de Pernambuco (UFPE) e Universidade Federal Rural de Pernambuco (UFRPE), a partir dos critérios recomendados pelo Modelo de Acessibilidade em Governo Eletrônico (eMAG) criado pelo Governo Federal do Brasil.

Os referidos sites mencionados servem ao propósito público de prover informações para estudantes, professores, pesquisadores, técnicos e a sociedade em geral, sobre conteúdos referentes às instituições que os administram. São espaços de transparência, de promoção da cidadania e prestação de serviços das universidades públicas para a população. Assim, com essas características, esses dispositivos tecnológicos devem estar adequados ao atendimento de todas as pessoas que deles desejam fazer uso, sem distinção de qualquer natureza, conforme estabelece a Constituição Federal do Brasil de 1988 (BRASIL, 1988).

Partilhando das preocupações com o acesso e o uso da informação, a Ciência da Informação (CI) e a Tecnologia da Informação (TI) exercem um papel fundamental no que diz respeito à disseminação e democratização da informação. Essas ciências são importantes, pois há uma crença comum sobre o lugar central do conhecimento na humanidade e que a disseminação e o acesso à informação são atividades complementares, tendo em vista que ambas se retroalimentam na sociedade da informação. Sobre isto, Lara Filho (2006), lembra que as atuais tecnologias de comunicação, como a $W e b$, valem-se de dispositivos digitais que solicitam uma ação do usuário para que se desencadeie uma ação como resposta, potencializando as ideias de interatividade e participação, porém, para as pessoas com deficiência, esses princípios e a noção de sociedade da informação, muitas vezes, mostra-se como uma falácia, pois nem todos são integrados adequadamente aos recursos informacionais que precisam.

Historicamente, o progresso do homem está associado ao desenvolvimento das tecnologias e à constante busca pelo controle da informação em processos automatizados. Neste cenário, nota-se que houve uma grande evolução nos últimos anos, sobretudo, com as possibilidades que foram abertas pela Internet. De todo modo, percebe-se que mesmo com toda a evolução digital, alguns públicos ainda encontram obstáculos, que em muitos casos, os colocam em posição de exclusão no ambiente digital, haja vista que os produtos e serviços de informação não foram concebidos para as suas necessidades.

Para a população deficiente, o acesso à informação significa autonomia e liberdade. É a possibilidade de ter acesso à cidadania e minimizar as disparidades no acesso às oportunidades. Como afirmam Rocha e Baranauskas (2003), faz-se uso principalmente da visão - para leitura da tela, e do sistema motor - para uso do teclado e do mouse. Portanto, pessoas portadoras de deficiências têm o acesso à informação tremendamente dificultado. Um dos principais fatores de inacessibilidade às informações encontrado por este público é a não aderência dos sites aos padrões de acessibilidade. Este impeditivo desfavorece o acesso a serviços como educação, saúde e emprego, impactando principalmente na aquisição de conhecimento, elemento transformador que dá sentido aos sujeitos no mundo. 
Partindo do conceito de Barreto (1999), uma vez que as pessoas com deficiência são "agentes de informação", entende-se que a informação é uma ferramenta de transformação do ser humano, que ao ser adequadamente assimilada, produz conhecimento, modifica o estoque mental de informações do indivíduo e traz benefícios ao seu desenvolvimento e ao desenvolvimento da sociedade em que ele vive. Daí a importância de se garantir o acesso à informação a todos.

Partindo de tais pressupostos, esse artigo justifica-se pelo olhar social que emprega, trazendo à tona um assunto de interesse da sociedade, porém, que é negligenciado no contexto das políticas e da prestação dos serviços públicos, à medida em que se torna excluído o deficiente devido às suas necessidades específicas. Espera-se com esse estudo promover o papel do deficiente na sociedade e reforçar a importância da implementação de princípios de acessibilidade nos dispositivos públicos de informação e comunicação, como é o caso dos sites.

\section{ACESSIBILIDADE E O ACESSO À INFORMAÇÃO NA WEB (À WEB)}

O termo acessibilidade pode ser entendido sob diferentes perspectivas, porém, de uma maneira geral, constata-se que a acessibilidade é: [...] o direito de eliminação de barreiras arquitetônicas, de disponibilidade de comunicação, de acesso físico, de equipamentos e programas adequados, de conteúdo e apresentação da informação em formatos alternativos (ACESSIBILIDADE BRASIL, 2013). Frisa-se que a acessibilidade significa a capacidade de um produto ser acessível ao usuário, independentemente de suas limitações, bem como, do seu contexto sociocultural e econômico. Nesse sentido, a acessibilidade passa a ser entendida como sinônimo de aproximação, um meio de disponibilizar a cada usuário interfaces que respeitem suas necessidades e preferências (ABRA, 2012).

A acessibilidade à web significa a capacidade de um website permitir o acesso a seu conteúdo por todos os tipos de pessoas, com deficiência ou não, de forma satisfatória e adequada. Tem como um dos princípios básicos a flexibilização para atender aos diversos tipos de necessidades e preferências. Para Marques (2014), um dos objetivos da acessibilidade à web é tornar pessoas deficientes incluídas no ambiente web, de modo que possam perceber, entender, navegar e interagir de uma maneira efetiva, bem como criar e contribuir com conteúdos. Além disso, a acessibilidade preocupa-se com todos os tipos de necessidade especial, incluindo as visuais, auditivas, físicas, de fala, cognitivas e neurológicas.

Cabe aqui um esclarecimento terminológico em relação aos termos deficiência e necessidades especiais. O termo "necessidades especiais" é amplo e não deve ser tratado como sinônimo de pessoa com deficiência. De acordo com Sassaki (2005), as necessidades especiais: autismo, dificuldades de aprendizagem, superdotação, distúrbios emocionais, entre outros, resultam de condições atípicas. Já as deficiências podem ser classificadas em cognitivas (síndrome de down), físicas (lesões neurológicas, neuromusculares, ortopédicas) e sensoriais (cegueira, baixa visão, daltonismo, surdez). De acordo com Coneglian e Casarin (2014), os termos adequados para se referir ao tema são: deficiente/deficiência/pessoa com deficiência; deficiente auditivo/surdo; deficiente mental/intelectual; deficiente visual/cego/baixa visão; deficiente físico; deficiência múltipla; surdocegueira; necessidades especiais e necessidades educacionais especiais.

Quando se trata de acessibilidade à web, as seguintes deficiências estão em foco: visual (cegueira, baixa visão e daltonismo, convulsão visual); motora (impossibilidade de usar as mãos, tremores nos membros superiores); auditivas (surdez ou pouca audição); cognitiva/intelectual (dificuldades de aprendizagem, dislexia).

De maneira prática, o simples fato do site respeitar os padrões de acessibilidade, já podem trazer uma enorme diferença para a vida deste grupo de pessoas, como por exemplo, uma 
imagem em tamanho grande pode facilitar a navegação de um usuário com baixa visão, da mesma forma que destaques de fonte e de cor ajudam a compreensão dos conteúdos por pessoas daltônicas. Na mesma linha, Ferreira e Nunes (2008) afirmam que as pessoas com deficiência visual, naturalmente, não utilizam o mouse para acesso aos conteúdos, os mesmos valem-se do ouvido ou do tato (por meio de dispositivo braile) para leitura das informações, recorrendo às teclas de atalho do teclado para navegar pelo conteúdo. Quando o site dispõe de atalhos no teclado, isto ajuda o usuário que não pode usar o mouse, e também, legendas e versões em linguagem de sinais em vídeos ajudam pessoas surdas ou com baixa audição a entender o que está sendo apresentado.

No Brasil, a acessibilidade à web é regulamentada pelo decreto 5.296 de 2 de dezembro de 2004 que regulamenta as Leis $n^{\circ} 10.048$, de 8 de novembro de 2000, que dá prioridade de atendimento às pessoas que especifica, e $\mathrm{n}^{\circ} 10.098$, de 19 de dezembro de 2000, que estabelece normas gerais e critérios básicos para a promoção da acessibilidade.

Já a Lei de Acesso à Informação n ${ }^{0} 12.527$, de 18 de novembro de 2011 em seu artigo $8^{\circ}$ adverte que "deverão, na forma de regulamento, atender, entre outros, aos seguintes requisitos: (...) adotar as medidas necessárias para garantir a acessibilidade de conteúdo para pessoas com deficiência". E o Decreto de $n^{\circ} 7.724$, de 16 de maio de 2012, que regulamentou a Lei de Acesso à Informação, indica no parágrafo $3^{\circ}$ do seu artigo $8^{\circ}$ : "Os sítios na Internet dos órgãos e entidades deverão, em cumprimento às normas estabelecidas pelo Ministério do Planejamento, Orçamento e Gestão [...]” (BRASIL, 2014).

A acessibilidade na web (ou à web) é uma questão fundamental, visto que permite a participação de pessoas com deficiências na sociedade e estimula a criação de oportunidades para todos. Isso inclui não somente as pessoas com deficiências visuais, mas também, pessoas com restrições físicas temporárias (braço quebrado, cirurgia no olho etc), pessoas idosas, ou casos de conexão lenta (MARQUES, 2014), fazendo com que elas usufruam dos serviços públicos com autonomia e independência.

Para garantir o acesso aos sites governamentais às pessoas com deficiência, o governo brasileiro, inspirado nas diretrizes do W3C e juntamente com um comitê da ABNT (Associação Brasileira de Normas Técnicas) desenvolveu um modelo de acessibilidade brasileira, o eMAG, para que o acesso aos sites e portais ocorresse de forma padronizada e adequada. No entanto, infelizmente no Brasil a quantidade de sites que possuem navegação de forma acessível é mínima, mesmo com as recomendações e exigências do Governo, muitos de seus próprios sites, não estão disponíveis de maneira acessível, como é o caso apresentado nesta pesquisa.

\section{MODELO DE ACESSIBILIDADE EM GOVERNO ELETRÔNICO - eMAG}

Criado pelo Governo federal para fins de inclusão de parcela significativa da população brasileira que apresenta algum tipo de deficiência, o eMAG tem o objetivo de guiar o desenvolvimento e a adaptação de conteúdos digitais de sites e portais pertencentes ao Governo Federal, visando garantir o acesso a todos (BRASIL, 2014). Toda instituição federal deve utilizá-lo ao desenvolver ou realizar manutenção em suas plataformas digitais, de modo que o processo de acessibilidade seja padronizado com padrões internacionais das Diretrizes de Acessibilidade para o Conteúdo da Web - Web Content Accessibility Guidelines (WCAG).

No caso de pessoas com deficiência, quatro situações podem ser vivenciadas: acesso ao computador sem o mouse (deficiência visual, dificuldade no controle dos movimentos); acesso ao computador sem teclado (ausência de membros superiores); acesso ao computador sem monitor (deficiência visual); acesso ao computador sem áudio (deficiência auditiva). Diferentemente dos outros instrumentos e ferramentas de avaliação de sites, o eMAG não possui re- 
comendações por níveis de prioridade, mas classificam-se nas seguintes categorias: marcação, comportamento, conteúdo/informação, apresentação/design, multimídia e formulário.

Além das recomendações, o guia ainda define um conjunto de elementos que devem estar presentes em todas as páginas dos sites governamentais, tais como: página com descrição dos recursos de acessibilidade, teclas de atalho, barra de acessibilidade, apresentação do mapa do sítio, apresentação de formulário, conteúdo alternativo para imagens e apresentação de documentos.

A primeira versão do eMAG foi desenvolvida baseada em diversas normas internacionais de acessibilidade digital e norteada pelas legislações de promoção a acessibilidade. Foi elaborada pelo Departamento de Governo Eletrônico em parceria com a ONG Acessibilidade Brasil, sendo disponibilizada para o público no ano de 2005. Em 2007, a Portaria $n^{\circ} 3$, de 7 de maio, tornou sua observância obrigatória nos sítios e portais do governo brasileiro. As versões 1.4 e 2.0 eram divididas em dois documentos: uma voltada para o entendimento dos cidadãos e outra direcionada aos desenvolvedores de sites. No entanto, devido a alguns inconvenientes que surgiram a partir da terceira versão, a disponibilização foi feita em apenas um único documento. Em 2011, foi lançada a versão 3.0, apoiada na WCAG 2.0, pensada e planejada de maneira a atender as necessidades locais. Em 2014, foi lançada a versão 3.1, a qual é utilizada nesta pesquisa (BRASIL, 2014).

Araújo (2015) alerta que a adoção das orientações do guia eMAG é um importante passo no processo de universalização do acesso às iniciativas de Governo na web, além de serem "medidas de baixo custo, justas e equitativas, perfeitamente alinhadas com os princípios constitucionais da impessoalidade e eficiência". Considerando-se que as recomendações do eMAG devem ser cumpridas, mas que não estão sendo devidamente seguidas pelos sites governamentais, este trabalho visa fazer uma avaliação de sites de duas Universidades Federais localizadas na cidade de Recife, a fim de verificar em qual nível de acessibilidade se encontram esses sites.

\section{ACESSO À INFORMAÇÃO}

O acesso à informação constitui um direito do cidadão previsto no Art. $5^{\circ}$ da Constituição da República Federativa Brasil, incisos: XIV: "é assegurado a todos o acesso à informação e resguardado o sigilo da fonte, quando necessário ao exercício da profissão" e XXXIII: "todos têm direito a receber dos órgãos públicos informações de seu interesse particular ou de interesse coletivo ou geral, que serão prestadas no prazo da lei, sob pena de responsabilidade, ressalvadas aquelas cujo sigilo seja imprescindível à segurança da sociedade e do Estado". No caput deste mesmo artigo tem-se que "todos são iguais perante a lei, sem distinção de qualquer natureza, garantindo-se aos brasileiros e aos estrangeiros residentes no País a inviolabilidade do direito à vida, à liberdade, à igualdade, à segurança e à propriedade" (BRASIL, 1988).

Logo, quando o website de uma universidade pública, seja UFPE ou UFRPE, não atendem às normas de acessibilidade, o efeito disso é o prejuízo a um direito fundamental da população, em especial, das minorias, impedindo o acesso à recursos de informação necessários para a cidadania dos indivíduos. Deste modo, a administração das instituições públicas tem o dever de cumprir as normas de acessibilidade estabelecidas, mesmo aquelas que não são de caráter compulsório, dando o necessário suporte àqueles que apresentam deficiências e necessidade especiais, e no caso das universidades, contribuindo para a democratização do ensino superior e do conhecimento.

A participação popular no ambiente acadêmico, independentemente de suas diferenças, é essencial para a manutenção de uma sociedade democrática de direito e para o desenvolvimento do conhecimento científico de um país. Isto representa a promoção de cidadania e a 
garantia do exercício de um ambiente pautado na isonomia, procedimentos iguais para os iguais e desiguais para desiguais, objetivando que todos possam ser "sujeitos de si mesmos", realizando seus sonhos e tendo no Estado um amparo para o seu progresso. Sob o aspecto técnico computacional, há uma quantidade enorme de recursos existentes que podem contribuir para o cumprimento de tais princípios, por isso que esta discussão deve ser estabelecida em frentes interdisciplinares, que envolvam as áreas de: CI, TI, Pedagogia, Direito, Administração, Políticas Públicas e outros campos de interesse.

\section{PERCURSO METODOLÓGICO}

A pesquisa tem caráter exploratória, valendo-se de uma abordagem qualitativa, pautada na observação e análise das interfaces de interação entre humanos e computadores nos dois sites estudados, da UFPE e UFRPE . A escolha dessas duas instituições se deu pela importância que ambas possuem na sociedade pernambucana, como universidades de padrão internacional em relação à produção científica e formação de profissionais.

O objetivo do estudo não foi depreciar os sítios institucionais das Universidades, mas pelo contrário, promovê-los, ressaltando sua importância, em especial, no que tange às possibilidades de acesso por um público plural, que envolve pessoas com deficiência, porém, para isso, algumas adequações precisam ser realizadas. Assim, conhecendo previamente a realidade das instituições, surgiu essa pesquisa, visando evidenciar e chamar a atenção dos gestores para a acessibilidade.

Na caracterização institucional viu-se que a UFPE reúne mais de 40 mil pessoas, entre professores, servidores técnico-administrativos e alunos de graduação e pós-graduação, distribuídos em três campi: Recife, Caruaru e Vitória de Santo Antão. No Campus Recife, são mais de 40 prédios. A UFPE oferece 100 cursos de graduação presenciais distribuídos em 12 centros e mais cinco cursos de graduação na modalidade a distância (UFPE, 2016). Deste modo, a UFPE é a instituição de ensino superior mais representativa de Pernambuco.

A UFRPE é composta por mil professores, 900 técnicos e 17 mil estudantes, desenvolvendo atividades voltadas para a busca intensa do conhecimento científico nas áreas de Ciências Agrárias, Humanas e Sociais, Biológicas, Exatas e da Terra. A Rural, como é conhecida, tem 45 cursos de graduação e um amplo leque de cursos de pós-graduação e Educação a Distância, sendo reconhecida como uma das principais instituições de ensino superior do estado (UFRPE, 2016).

Para o levantamento dos dados sobre os sites foi elaborada uma planilha como modelo de observação sistemática orientada por categorias e baseada nos conceitos da publicação "eMAG - Modelo de Acessibilidade em Governo Eletrônico", versão 3.1, publicada em abril de 2014 com o objetivo de promover a implementação da acessibilidade digital de forma fácil e padronizada, coerente com as necessidades brasileiras e em conformidade com os padrões internacionais (BRASIL, 2014).

As categorias estabelecidas como critério de avaliação foram: a) Disponibilizar todas as funções da página via teclado; b) Identificar o idioma principal da página; c) Fornecer alternativa para vídeo; d) Fornecer alternativa para áudio; e) Oferecer áudio descrição para vídeo pré-gravado; f) Primeira folha de contraste; g) Barra de acessibilidade; h) Página de descrição com os recursos de acessibilidade.

As análises foram realizadas por meio da técnica de observação e avaliação das interfaces dos portais durante o mês de julho de 2016. Os resultados foram estruturados em um quadro com as opções "sim", "não" e "em parte", referindo-se à conformidade dos sites aos critérios selecionados. 


\section{RESULTADOS E DISCUSSÃO}

Inicialmente, cabe ressaltar que a análise dos critérios não foi feita através de um instrumento ou software de avaliação de sites, a verificação foi feita empiricamente mediante o uso efetivo das páginas e categorias, a priori, definidas.

A discussão dos resultados está pautada nas principais situações de dificuldades de acesso que as pessoas com deficiência possuem, tais como: movimentos limitados das mãos (temporários ou definitivos), que utilizam um teclado adaptado com teclas maiores ou mouse especial para operar o computador; pessoas com baixa visão que usam recursos como ampliadores de tela; usuários cegos que utilizam softwares leitores de tela para fazer uso do computador, e por fim, usuários surdos que necessitam de descrição de áudio.

Desta feita, seguindo as recomendações do eMAG, foram estabelecidos os seguintes critérios de acessibilidade desejáveis para os sites: a) identificação do idioma principal da página; fornecimento de alternativa para vídeo; fornecimento de alternativa para áudio; oferecimento de áudio descrição para vídeo pré-gravado; primeira folha de contraste; barra de acessibilidade e página de descrição com os recursos de acessibilidade.

A partir disto, os resultados encontrados podem ser visualizados no Quadro 1 e expressam a síntese dos achados encontrados na pesquisa, comparando os resultados da UFPE com os da UFRPE.

Quadro 1 - Avaliação de acessibilidade dos sites da UFPE e UFRPE: comparação entre as categorias estabelecidas segundo o eMAG

\begin{tabular}{|l|l|l|}
\hline \multicolumn{1}{|c|}{ Categorias } & UFPE & UFRPE \\
\multicolumn{1}{|c|}{ Universidades Federais de Recife } & & \\
\hline Disponibilizar todas as funções da página via teclado & NÃO & NÃO \\
\hline Identificar o idioma principal da página & SIM & NĀO \\
\hline Fornecer alternativa para video & NÃO & NÃO \\
\hline Fornecer alternativa para áudio & NÃO & SIM \\
\hline Oferecer áudio descrição para video pré-gravado & NÃO & NÃO \\
\hline Primeira folha de contraste & EM PARTE & EM PARTE \\
\hline Barra de acessibilidade & NÃO & NÃO \\
\hline Página de descrição com os recursos de acessibilidade & NÃO & NÃO \\
\hline
\end{tabular}

Fonte: Elaboração dos autores (2016)

O Quadro 1 aponta o desempenho negativo de ambas as instituições no que tange à acessibilidade e usabilidade, demonstrando que ainda há muito o que evoluir para que o público com deficiência possa acessar de maneira autônoma as informações disponíveis pela UFPE e UFRPE em seus respectivos sites. Tal panorama apenas contribui para a exclusão do público com deficiência, em certos casos, dificultando o acesso a informações sobre seleções, oportunidades, concursos, eventos etc. Ao considerar-se o fenômeno cibercultural difundido no tempo presente, em que os produtos e serviços encontram-se cada vez mais alocados no ambiente web, vê-se que as restrições mapeadas no Quadro 1, restringem não só a acessibilidade à serviços, 
mas dificulta aos deficientes a obtenção de uma vida plena e autônoma, levando-o a uma situação de desvantagem (AMARAL et al., 2012)

Ao analisar item a item, verifica-se que o uso do teclado para acessar os sites deveria ser feito por meio do atributo "alt", que somado com outras letras ou números permitiria o acesso e navegação a todos os menus e itens de uma página. Sobre isto, constatou-se que nenhum dos sites avaliados apresentou tal funcionalidade.

Em relação ao idioma principal da página, apenas a UFPE apresentou esta funcionalidade, o único item em que a instituição se destacou positivamente. Esse recurso é imprescindível para que se inicie uma navegação, pois a sua inexistência desabilita e impede o acesso completo ao usuário que não domina a linguagem padrão do site. Segundo o WCAG, essa função permite tornar o conteúdo de texto legível e compreensível (ROCHA; DUARTE, 2012).

Concernente às alternativas para áudio, a audiodescrição pré-gravada é de extrema importância para os usuários cegos e surdos, pois oferecem alternativa de legendas e descrição de imagens e sons para as pessoas que demandam esses recursos. Neste quesito, verificou-se que apenas o site da UFRPE fornecia oferta de áudio. Um resultado ínfimo diante dos inúmeros desafios a serem conquistados em termos de acessibilidade. A audiodescrição como tecnologia social é uma estratégia de inserção cultural e educacional que permite viabilizar a acessibilidade dos deficientes visuais a filmes, peças de teatro, espetáculos de dança, programas de televisão etc (DAVID; HAUTEQUESTT; KASTRUP, 2012), inclusive, servindo também para surdos a partir da Linguagem Brasileira de Sinais - LIBRAS.

Quanto aos recursos de contraste, são importantes por permitirem acesso mais confortável às pessoas que possuem baixa visão ou daltonismo, e neste item ambos os sites atenderam apenas parcialmente, pois, apesar de haver diferenciação entre as cores e os níveis, o site não apresenta a barra de acessibilidade contendo a opção de contraste, o que dificulta o seu acesso para públicos específicos.

Não menos importante, analisou-se a existência da barra de acessibilidade, item fundamental, pois, logo que o indivíduo acessa o site, exibem-se quais as ferramentas de acessibilidade estão disponíveis, dando destaque aos recursos existentes. Sua ausência, portanto, sinaliza que dificilmente serão encontradas ferramentas de acessibilidade ao longo das diferentes seções do site (SILVA; RUE, 2015). Feita a análise, viu-se que nenhum dos sites apresentou recursos referentes a estes itens, demonstrando um baixíssimo grau de conformação aos critérios estabelecidos pelo eMAG, indispensáveis para a promoção da acessibilidade.

Em suma, ao compilaram-se os resultados, notou-se que o site da UFPE apresentou apenas um recurso completo e outro incompleto. Como ponto positivo da instituição, aponta-se a indicação do idioma com as opções para inglês, espanhol e português. Em contrapartida, não atendeu adequadamente a nenhum outro critério de acessibilidade.

Da mesma forma, o site da UFRPE apresentou apenas um recurso completo e outro incompleto. Observou-se que os vídeos continham legendas e que a página também apresentava um leve contraste entre os tons da página, mas não apresenta o recurso oficial de contraste na barra de acessibilidade do site, já que nem a possui. Portanto, todos os outros recursos analisados não foram encontrados no site, caracterizando-os como "sites de baixa acessibilidade".

\section{CONSIDERAÇÕES FINAIS}

As recomendações de acessibilidade da informação no ambiente Web visam atender qualquer tipo de pessoa e otimizar o tempo de busca e localização da informação. Obviamente, existe um impacto especial na vida das pessoas com deficiência, tendo em vista que diariamente 
elas já enfrentam problemas de exclusão e necessitam de políticas que as conduzam de maneira digna aos seus direitos, dando-lhes condições justas de acesso à informação e possibilidades de ingresso em oportunidades.

Ao restringir-se a análise a sites da área de educação pública/federal, buscou-se chamar a atenção para um problema ainda mais latente, que é o direito que as pessoas têm de se desenvolver intelectualmente e profissionalmente, independente de possuírem ou não deficiências. $\mathrm{Na}$ visão dos autores deste trabalho, todos somos deficientes, pois em algum grau possuímos incompletudes, sejam elas latentes ou não, e isto só reforça a nossa condição de igualdade enquanto partícipes de um conjunto imperfeito denominado "humanidade". Obviamente, esse discurso não exclui o fato de o Brasil possuir 46 milhões de brasileiros com algum grau de deficiência (BRASIL, 2010), que demandam políticas específicas e que fogem da regra da regra geral da sociedade.

A partir dos resultados, conclui-se que o cumprimento do eMAG seria a solução para mitigar os problemas enfrentados diariamente pelos deficientes no acesso à informação dos sites avaliados. Por conseguinte, nota-se que atualmente, no quesito acessibilidade, as Universidades Públicas Federais do Recife ainda estão bem distantes das boas práticas desejáveis. Frente às recomendações e legislações estabelecidas em âmbito nacional pelas leis de acessibilidade e acesso à informação, julga-se que ambos os sites possuem um nível baixo de acessibilidade.

A ausência de acessibilidade está intrinsecamente relacionada ao princípio da usabilidade social, que tem como principal objetivo apresentar de forma acessível e com eficiência e eficácia as configurações relativas às alternativas de acesso às informações contidas em um site. Por fim, verifica-se a necessidade de que os desenvolvedores e administradores dos sites realizem uma atualização dos mesmos, pois a informação circulante neles é um direito de todos, principalmente para aqueles que pretendem ingressar ou que já fazem parte do universo acadêmico e possuem algum tipo de deficiência.

Enquanto limitação, este estudo restringiu-se a um universo circunscrito visando oportunizar em tempo hábil a possibilidade de ampliar a divulgação desta causa em meio acadêmico. De todo modo, pretende-se em estudos futuros realizar uma análise envolvendo mais sites, e coletando informações dos próprios usuários sobre as barreiras impostas ao acesso à informação, reforçando o caráter empírico deste projeto, que se vale da constatação de questões práticas para transformar a própria práxis e influenciar diretamente a vida do público interessado.

\section{REFERÊNCIAS}

ABRA. Associação Brasileira de Acessibilidade. 2014. Disponível em: $<$ http://www.acessibilidade.org.br/>. Acesso em: 01 jan. 2016.

ACESSIBILIDADE BRASIL. O que é acessibilidade? 2013. Disponível em: $<$ http://www.acessibilidadebrasil.org.br/versao_anterior/index.php?itemid=45>. Acesso em: 01 jan. 2016.

AMARAL, F. L. J. S. et al. Acessibilidade de pessoas com deficiência ou restrição permanente de mobilidade ao SUS. Ciênc. saúde coletiva, Rio de Janeiro, v. 17, n. 7, p. 18331840, Jul. 2012. Disponível em: <http://www.scielo.br/scielo.php?script=sci_arttext\&pi$\mathrm{d}=\mathrm{S} 1413-81232012000700022 \& \operatorname{lng}=\mathrm{en} \& \mathrm{nrm}=\mathrm{iso}>$. Acesso em: 01 jan. 2016.

ARAÚJO, R. [E-GOV] E-PING E E-MAG: exemplos de redações. 2015. Disponível em: <http:// www.itnerante.com.br/profiles/blogs/e-gov-e-ping-e-e-mag-exemplos-de-reda-es $>$. Acesso em 23 jul. 2016. 
BARRETO, A. A. A oferta e a demanda da informação: condições técnicas, econômicas e políticas. Ciência da Informação, Brasília, v. 28, n. 2, p. 168-173, 1999. Disponível em: <http:// revista.ibict.br/ciinf/article/view/847/880>. Acesso em 23 jul. 2016.

BRASIL. Constituição (1988). Constituição da República Federativa do Brasil de 1988. Brasília, DF: Presidência da República, 1988. Disponível em: <http://www.planalto.gov.br/ccivil_03/ Constituicao/ Constituiçao.htm>. Acesso em: 1 jan. 2016.

BRASIL. Ministério do Planejamento, Orçamento e Gestão. Secretaria de Logística e Tecnologia da Informação. Gov.br e-mag versão 3.1: modelo de acessibilidade em governo eletrônico. Brasília, DF, 2014. Disponível em: http://www.governoeletronico.gov.br/eixos-de-atuacao/gestao/acessibilidade/emag-modelo-de-acessibilidade-em-governo-eletronico. Acesso em 23 jul. 2016.

CONEGLIAN, A. L. O; CASARIN, H. de C. S. Deficientes como usuários de informação. In: CASARIN, H. de C. S (org.) Estudos de usuários da informação. Brasília: Thesaurus, 2014.

DAVID, J.; HAUTEQUESTT, F.; KASTRUP, V. Audiodescrição de filmes: experiência, objetividade e acessibilidade cultural. Fractal: Revista de Psicologia, Rio de Janeiro, v. 24, n. 1, p. 125-142, Abr. 2012. Disponível em: $<$ http://www.scielo.br/scielo.php?script=sci_arttext\&pi$\mathrm{d}=\mathrm{S} 1984-02922012000100009 \& \operatorname{lng}=\mathrm{en} \& \mathrm{nrm}=\mathrm{iso}>$. Acesso em 23 jul. 2016.

FERREIRA, S. B. L.; NUNES, R. R. E-Usabilidade. Rio de Janeiro: LTC Editora, 2008. 196 p.

INSTITUTO BRASILEIRO DE GEOGRAFIA E ESTATÍSTICA (IBGE). Pessoas com Deficiência. 2010. Disponível em: <https://educa.ibge.gov.br/jovens/conheca-o-brasil/populacao/ 20551-pessoas-com-deficiencia.html>. Acesso em: 01 jan. 2016.

LARA FILHO, D. Museu: de espelho do mundo a espaço relacional. 2006. 139 f. Dissertação (Mestrado) - Curso de Ciência da Informação, Escola de Comunicação e Artes, Universidade de São Paulo, 2006. Disponível em: <https://teses.usp.br/teses/disponiveis/27/27151/tde-30112006105557/pt-br.php>. Acesso em: 20 jul. 2016.

MARQUES, D. Formulários acessíveis com wai-aria. Disponível em: $<$ http://www.acessibiteca. uff.br/?p=1484>. 2014. Acesso em: 23 jul. 2016.

ROCHA, H. V.; BARANAUSKAS, M. C. Design e Avaliação de Interfaces Humano-Computador. Unicamp, 2003. Disponível em: <https://odisseu.nied.unicamp.br/wp-content/uploads/ other-files/livro-design-avaliacao-interfaces.zip>. Acesso em: 23 jul. 2016.

ROCHA, J. A. P.; DUARTE, A. B. S. Diretrizes de acessibilidade web: um estudo comparativo entre as WCAG 2.0 e o e-MAG 3.0. Inclusão Social, v. 5, n. 2, 2012. Disponível em: <http:// revista.ibict.br/inclusao/article/view/1678>. Acesso em: 23 jul. 2016.

SASSAKI, R. K. Inclusão: construindo uma sociedade para todos. 6. ed. Rio de Janeiro: WVA, 2005.

SILVA, R. L.; RUE, L. A. A acessibilidade nos sites do Poder Executivo estadual à luz dos direitos fundamentais das pessoas com deficiência. Revista de Administração Pública, v. 49, n. 2, p. 315-336, 2015. Disponível em: <http://www.scielo.br/pdf/rap/v49n2/0034-7612rap-49-02-00315.pdf>. Acesso em: 23 jul. 2016. 
TORRES, E. F.; MAZZONI, A. A.; ALVES, J. B. da. M. A acessibilidade à informação no espaço digital. Ciência da Informação, Brasília, v. 31, n. 3, p. 83-91, Set. 2002. Disponível em: http://www. scielo.br/scielo.php?script $=$ sci_arttext\&pid=S0100-19652002000300009\&lng=en\&nrm=iso. Acesso em: 18 jul. 2016.

UNIVERSIDADE FEDERAL DE PERNAMBUCO. A instituição. 2016. Disponível em: $<$ https://www.ufpe.br/ufpenova/index.php?option=com_content\&view=article\&id=99\&Itemid=178>. Acesso em: 18 jul. 2016.

UNIVERSIDADE FEDERAL RURAL DE PERNAMBUCO. Apresentação. 2016. Disponível em: $<$ http://www.ufrpe.br/br/content/apresenta\%C3\%A7\%C3\%A3o $>$. Acesso em: 18 jul. 2016. 